\title{
Supercritical cyclic steam stimulation of wellbore temperature and pressure distribution in Lukeqin oilfield
}

\author{
Jun Zhang, Nini Liu* \\ College of Technology \& Engineering, Yangtze University, Jingzhou 434023, China
}

Corresponding Author Email: 42831785@qq.com

https://doi.org/10.18280/ijht.360133

Received: 7 August 2017

Accepted: 18 October 2017

\section{Keywords:}

supercritical cyclic steam stimulation (CSS), Wellbore temperature, Wellbore pressure.

\begin{abstract}
This paper aims to optimize the injection temperature and pressure of supercritical steam. For this purpose, the author acquired the variations of the supercritical steam parameters (i.e. density, viscosity, thermal conductivity, enthalpy and specific heat) with temperatures and pressures, plotted the 3D diagrams of the variation patterns, and performed surface fittings of the results. On this basis, the calculation formulas were put forward for the physical parameters of steam under changing temperature and pressure. According to the theories of heat transfer, thermodynamics and fluid mechanics, a mathematical model of wellbore temperature and pressure was created for supercritical cyclic steam simulation (CSS), and discretized the calculation formulas by node analysis. Based on the model, a computation software was compiled for supercritical CSS, and applied to calculate the variation in wellbore temperature and pressure with well depths. The results show that the calculated temperature of wellbore steam decreased linearly, while the calculated pressure of the steam increased linearly, with the increase of well depth. Through comparison, the calculated results were found to be consistent with the distribution curves of the test results. The error between the two sets of results is extremely small. The research findings shed new light on the design and optimization of supercritical CSS parameters.
\end{abstract}

\section{INTRODUCTION}

Supercritical steam refers to the steam with temperature and pressure higher than the critical values $\left(374^{\circ} \mathrm{C}\right.$ and $\left.22.1 \mathrm{MPa}\right)$. The supercritical steam exists in an intermediate state between gas and liquid: it is denser than gas, and less viscous than liquid. These features make the supercritical steam a good medium for mass transfer and heat transfer.

In light of these, PetroChina Tuha Oilfield Company invented the technology of supercritical cyclic steam stimulation (CSS) for exploiting heavy oil reservoirs $[1,2]$. Compared to conventional CSS, the supercritical CSS can extract the heavy oil deeper than $2,000 \mathrm{~m}[3,4]$, realize a high daily yield of single well, and ensure a long period of stable production.

During the supercritical CSS, the varying temperature and pressure directly bear on the parameters of the supercritical steam in the wellbore, including density, viscosity, and thermal conductivity [5], and, in turn, affect the CSS performance. To optimize the injection temperature and pressure of supercritical steam, this paper explores the distribution law of temperature and pressure in the wellbore during supercritical steam injection. The research findings shed new light on the design and optimization of supercritical CSS parameters.

\section{THERMAL PROPERTIES OF SUPERCRITICAL STEAM}

The first step of supercritical CSS analysis is to understand the variation of supercritical steam parameters with temperatures and pressures. Hence, this section discusses the trends of density, specific heat, enthalpy, viscosity coefficient and thermal conductivity in near-critical and supercritical conditions. All these parameters were extracted from the NIST Reference Fluid Thermodynamic and Transport Properties Database.

\subsection{Change law of supercritical steam density}

Figures 1 and 2 present the variation of supercritical steam density with temperatures and pressures. Near the critical lines, the supercritical steam density plunged deeply with the rise in temperature and surged up with the increase of pressure. Thus, temperature is the key determinant of supercritical steam density. When the temperature fell between $375^{\circ} \mathrm{C}$ and $420^{\circ} \mathrm{C}$, the supercritical steam density changed drastically at any slight change of temperature or pressure. When the temperature was above $450^{\circ} \mathrm{C}$, the density exhibited a slow decline with the increase of temperature. Further increase in temperature led to a minor growth in supercritical steam density. It can be considered that the density remained basically the same after the temperature surpassed $450^{\circ} \mathrm{C}$. 


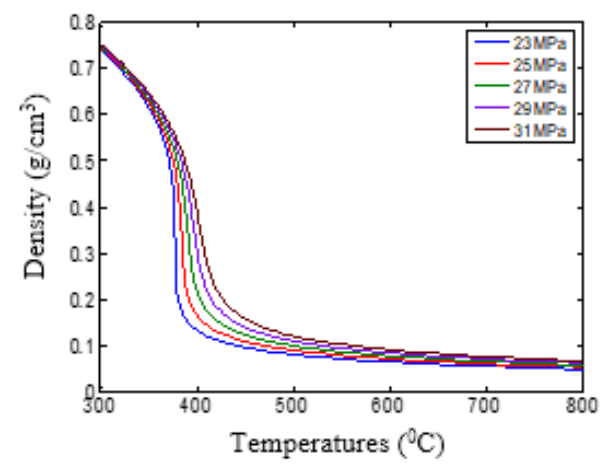

Figure 1. Supercritical steam density at different pressures

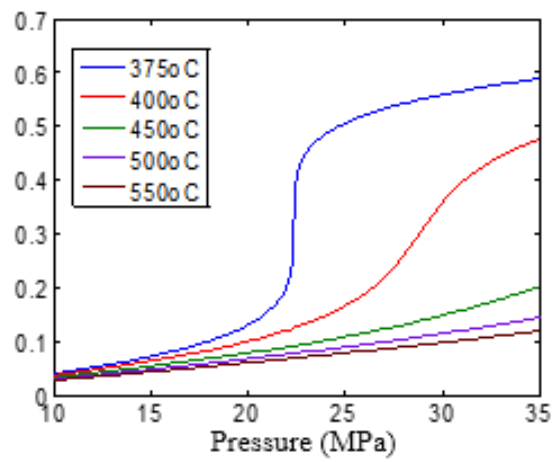

Figure 2. Supercritical steam density at different temperatures

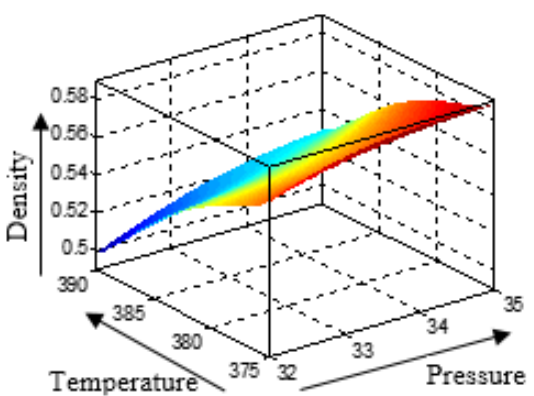

Figure 3. Correlations of supercritical steam density with temperature and pressure

Figure 3 is a $3 \mathrm{D}$ diagram of the correlations of supercritical steam density with temperature $\left(375^{\circ} \mathrm{C} \sim 390^{\circ} \mathrm{C}\right)$ and pressure (32MPa $35 \mathrm{MPa})$. It is clear that the density changed regularly with the two parameters. For instance, the supercritical steam density was $0.58776 \mathrm{~g} / \mathrm{cm}^{3}$ at the temperature of $375^{\circ} \mathrm{C}$ and the pressure of $35 \mathrm{MPa}$, and the lowest density of $0.49841 \mathrm{~g} / \mathrm{cm}^{3}$ at the temperature of $390^{\circ} \mathrm{C}$ and the pressure of $32 \mathrm{MPa}$. The surface was fitted by the following formula:

$\rho=2.28977-\frac{27.9466}{P^{1.5}}-0.004171 T$

where $\rho$ is the density of supercritical steam $\left(\mathrm{g} / \mathrm{cm}^{3}\right)$; T is the temperature of supercritical steam $\left({ }^{0} \mathrm{C}\right) ; \mathrm{P}$ is the pressure of supercritical steam (MPa). These parameters were also applied to the subsequent analysis.

\subsection{Change law of supercritical steam viscosity}

Figures 4 and 5 depict the variation of supercritical steam viscosity with temperatures and pressures. Near the critical lines, the supercritical steam viscosity underwent dramatic changes similar to those of the density. With the increase of temperature, the viscosity of supercritical steam firstly plunged deeply and then slightly moved up. With the increase of pressure, the viscosity exhibited a gradual increasing trend. However, the viscosity changed little and tended to be stable after the temperature exceeded $450^{\circ} \mathrm{C}$.

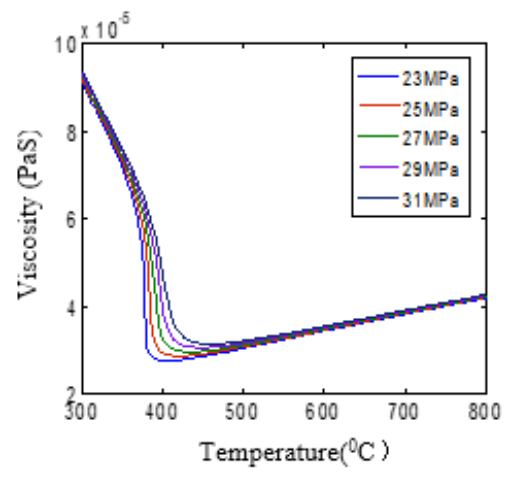

Figure 4. Supercritical steam viscosity at different temperatures

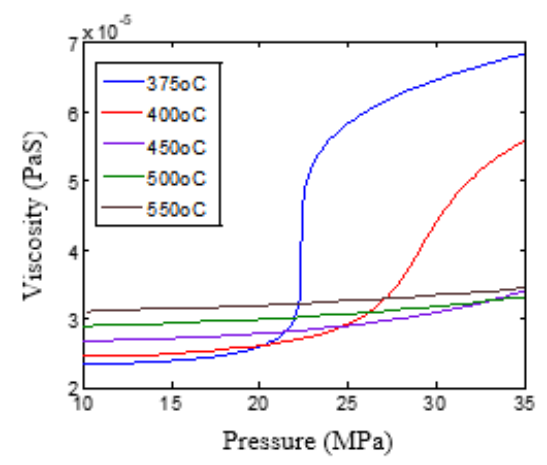

Figure 5. Supercritical steam viscosity at different pressures

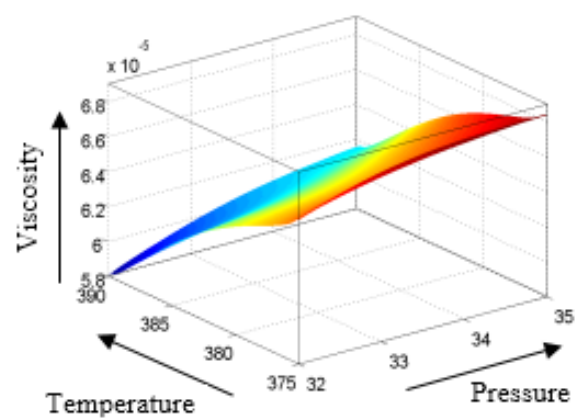

Figure 6. Correlations of supercritical steam viscosity with temperature and pressure

Figure 6 is a $3 \mathrm{D}$ diagram of the correlations of supercritical steam viscosity with temperature $\left(375^{\circ} \mathrm{C} \sim 390^{\circ} \mathrm{C}\right)$ and pressure (32MPa 35MPa) [6]. It can be seen that the viscosity changed regularly with the two parameters. For example, the supercritical steam viscosity reached the maximum at the temperature of $375^{\circ} \mathrm{C}$ and the pressure of $35 \mathrm{MPa}$, and the 
minimum at the temperature of $390^{\circ} \mathrm{C}$ and the pressure of $32 \mathrm{MPa}$. The surface was fitted by the following formula:

$\mu=-0.0000539348-\frac{0.02004}{P^{2}}+\frac{1.01477}{T^{1.5}}$

where $\mu$ is the viscosity of supercritical steam $\left(p_{a} \cdot s\right)$.

\subsection{Change law of thermal conductivity}

Figures 7 and 8 display the variation of thermal conductivity at different temperatures and pressures. In general, the thermal conductivity decreased with the rise of temperature and increased with the increase of pressure. After the temperature reached $500^{\circ} \mathrm{C}$, the thermal conductivity basically remained unchanged. The local peak value of the thermal conductivity appeared near the critical lines. With the growth of pressure, the local peak showed a decreasing trend, and ceased to exist once the pressure reached $31 \mathrm{MPa}$.

Figure 9 is a 3D diagram of the correlations of thermal conductivity with temperature $\left(375^{\circ} \mathrm{C} \sim 390^{\circ} \mathrm{C}\right)$ and pressure $(32 \mathrm{MPa} \sim 35 \mathrm{MPa})$ [7]. Overall, the thermal conductivity is negatively correlated with the temperature, and positively with the pressure. After the temperature reached $500^{\circ} \mathrm{C}$, the thermal conductivity remained essentially constant. The surface was fitted by the following formula:

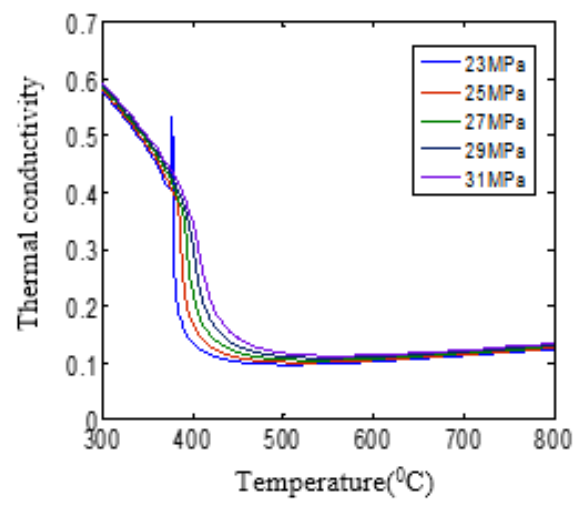

Figure 7. Supercritical steam thermal conductivity at different temperatures

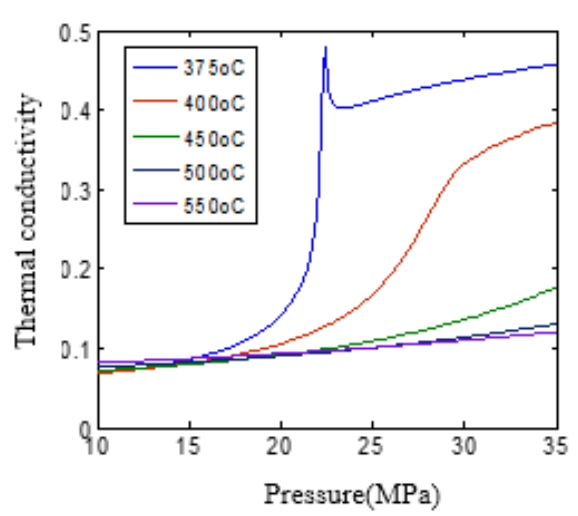

Figure 8. Supercritical steam thermal conductivity at different pressures

$\lambda=0.535175-7 \times 10^{-9} T^{3}+\frac{0.03038 P}{\ln P}$ where $\lambda$ is the thermal conductivity of supercritical steam $\left(\mathrm{W} / \mathrm{m}^{2} \cdot{ }^{0} \mathrm{c}\right)$

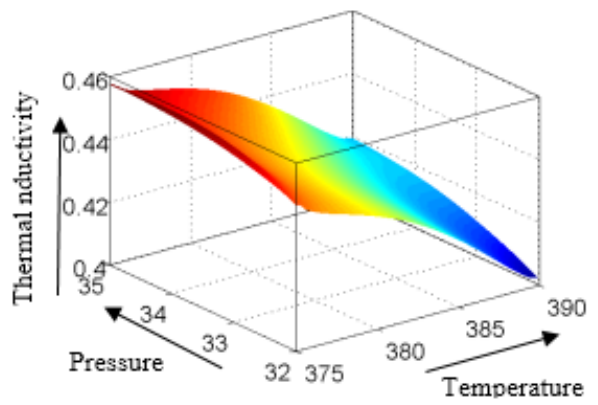

Figure 9. Correlations of thermal conductivity with temperature and pressure

\subsection{Change law of supercritical steam enthalpy}

Figures 10 and 11 illustrate the variation of the supercritical steam enthalpy (h) at different temperatures and pressures. Near the critical lines, the enthalpy underwent rapid changes: it increased with the increase of temperature and decreased with the increase of pressure. After the temperature surpassed $500^{\circ} \mathrm{C}$, the enthalpy exhibited a linear positive correlation with temperature and a linear negative correlation with pressure.

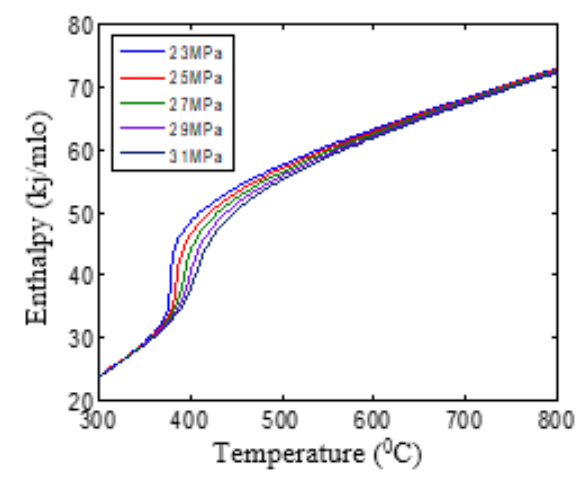

Figure 10. Supercritical steam enthalpy at different temperatures

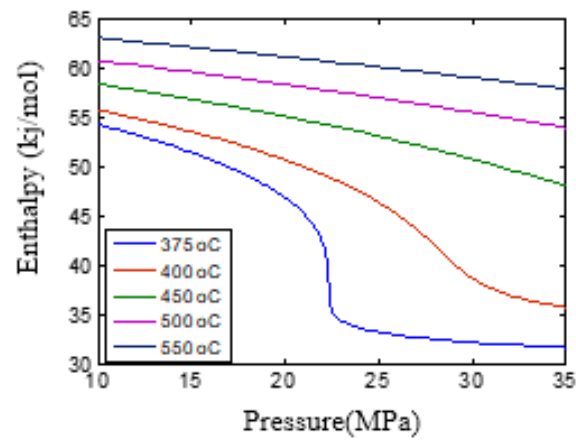

Figure 11. Supercritical steam enthalpy at different pressures

Figure 12 is a $3 \mathrm{D}$ diagram of the correlations of supercritical steam enthalpy with temperature $\left(375^{\circ} \mathrm{C} \sim 390^{\circ} \mathrm{C}\right)$ and pressure (32MPa 35MPa) [8]. Near the critical lines, the enthalpy increased rapidly with the increase of temperature, and decreased quickly with the rise of pressure. The surface was fitted by the following formula: 
$h=109.1574-1.24915 P+0.01767 P^{2}-\frac{20714.4821}{T}$

where $\mathrm{h}$ is the enthalpy of supercritical steam $(\mathrm{kj} / \mathrm{kg})$;

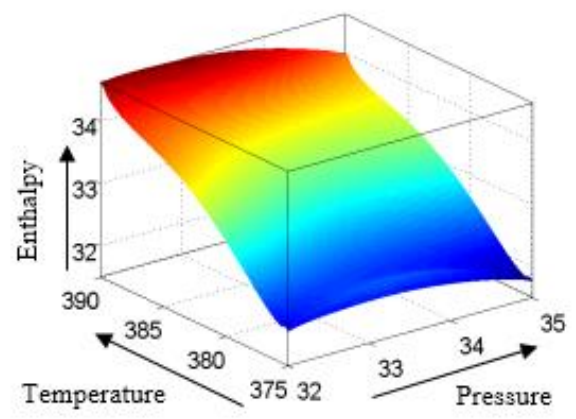

Figure 12. Correlations of supercritical steam enthalpy with temperature and pressure

\subsection{Change law of specific heat}

Figures 13 and 14 show the variation of the specific heat $\left(\mathrm{C}_{\mathrm{P}}\right)$ of supercritical steam with temperatures and pressures. As can be seen from the figures, the specific heat climbed up rapidly towards the peak value with the rise of temperature, and then gradually stabilized; with the increase in pressure, the specific heat first moved fast towards the peak value, then dropped quickly, and finally tended to stable.

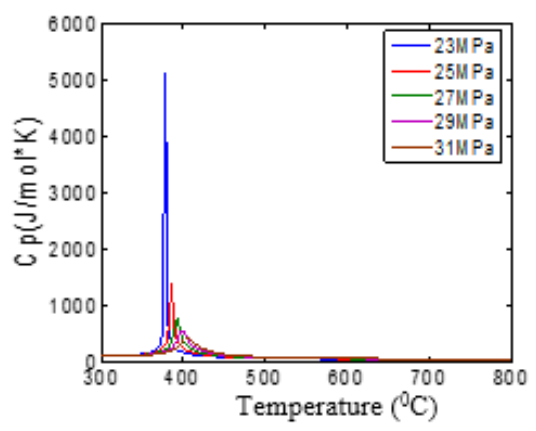

Figure 13. Specific heat at different temperatures

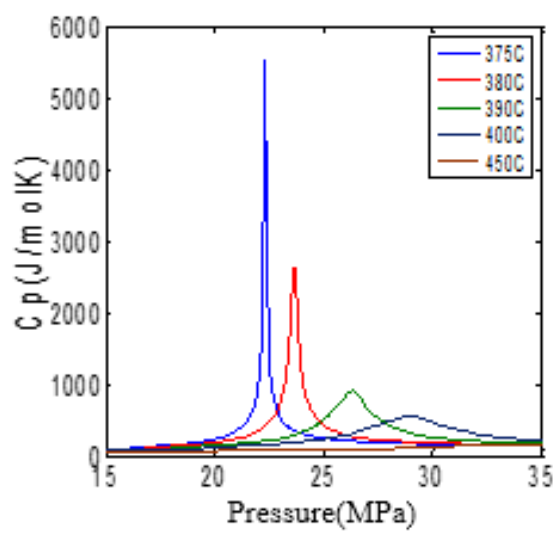

Figure 14. Specific heat at different pressures

In the supercritical range, there is a local maximum of the specific heat at each pressure in the supercritical range. The temperature corresponding to the maximum value is called the quasi-critical temperature. Figure 15 shows the relationship between the maximum specific heat and the pressure. It can be seen that, near the critical point, the maximum specific heat dropped sharply with the increase of pressure; the maximum value at the quasi-critical temperature is more than 1,000 times the specific heat at room temperature; the peak value ceased to exist when the pressure reached $23 \mathrm{MPa}$. The relationship between the maximum specific heat and the pressure can be expressed as:

$$
C_{P}=\frac{P-15.195}{0.02635 P^{2}-12.832}-1.2703
$$

where $C_{p}$ is the maximum specific heat $\left(\mathrm{kj} / \mathrm{kg} \cdot{ }^{0} \mathrm{C}\right)$; $\mathrm{P}$ is the pressure corresponding to the maximum specific heat $(\mathrm{MPa})$.

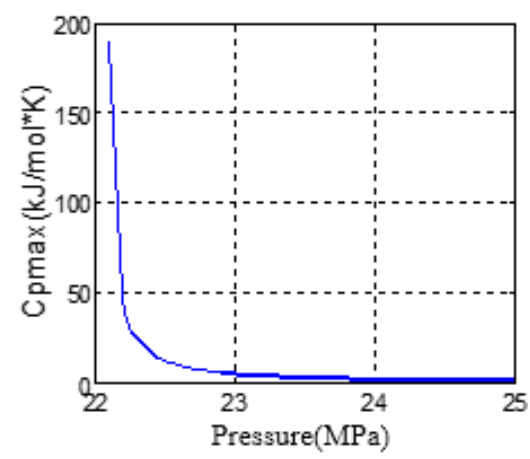

Figure 15. Maximum specific heat at different pressures

\section{MODEL CONSTRUCTION AND SOLUTION}

\subsection{Model construction}

Based on the target well, a coordinate system was set up for the well structure (Figure 16). In the system, the wellhead was taken as the origin and the vertical downward direction as the positive direction. Then, a microelement dy was obtained in the vertical direction. Let $d Q_{t}$ and $d Q_{r w}$ be the heat loss of fluid and the heat transferred from the steam per unit of time, respectively [10]. These parameters can be obtained by the law of conservation of energy [11]:

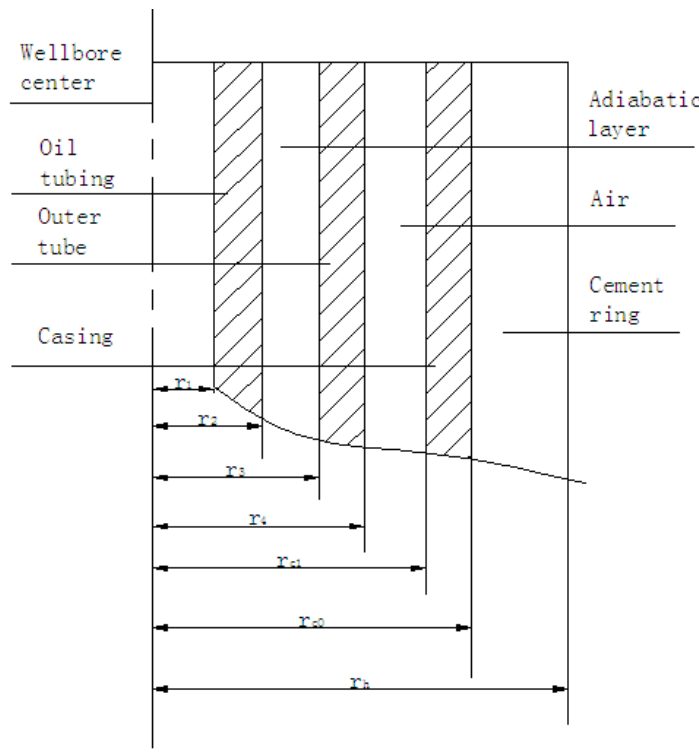

Figure 16. Well structure 
$W C_{p} \frac{d T_{s}}{d y}=2 \pi r_{2} U\left(T_{s}-T_{h}\right)$

where $\mathrm{W}$ is the mass flow $(\mathrm{kg} / \mathrm{s}) ; C_{p}$ is the specific heat $\left(\mathrm{kj} / \mathrm{kg} \cdot{ }^{0} \mathrm{C}\right) ; \quad T_{s}$ is the wellbore temperature $\left({ }^{0} \mathrm{C}\right) ; T_{h}$ is the formation temperature $\left({ }^{0} \mathrm{C}\right) ; r_{2}$ is the outer diameter of steam injection well $(\mathrm{m})$; $\mathrm{U}$ is the total heat transfer coefficient $\left(\mathrm{W} / \mathrm{m}^{2} \cdot{ }^{0} \mathrm{C}\right)$.

For simplicity, the thermal dissipation of the formation was described by the dimensionless thermal conduction function $\mathrm{f}(\mathrm{t})[12]$ :

$d Q_{r g}(y)=\frac{2 \pi \lambda_{e}\left(T_{h}-T_{e}\right)}{f(t)} d y$

where $\lambda_{e}$ is the thermal conductivity of the formation $\left(\mathrm{W} / \mathrm{m} \cdot{ }^{0} \mathrm{C}\right)$; $T_{e}$ is the temperature of the formation in $\mathrm{y}\left({ }^{0} \mathrm{C}\right) ; r_{h}$ is the outer diameter of the cement annulus (m); $\mathrm{t}$ is the time $(\mathrm{h})$.

According to the heat equilibrium $d Q_{t}=d Q_{r w}$ [13], we have:

$T_{h}=\frac{r_{2} U T_{s} f(t)+\lambda_{e} T_{e}}{\lambda_{e}+r_{2} U f(t)}$

Substituting formula (8) into formula (7), we have:

$W C_{p} \frac{d T_{s}}{d y}=2 \pi r_{2} U\left[\frac{T_{e}-T_{s}}{\lambda_{e}+r_{2} U f(t)}\right]$

The energy formula of supercritical steam flow in the wellbore is:

$\Delta p=\frac{\rho g-\tau_{f}}{\frac{W q_{v}}{A^{2} p}-1} \cdot \Delta y$

where $\rho$ is the density of steam $\left(\mathrm{g} / \mathrm{cm}^{3}\right)$; $\mathrm{g}$ is the gravitational acceleration; $q_{v}$ is the volume flow $\left(\mathrm{m}^{3} / \mathrm{s}\right)$; A is the cutting area of the wellbore $\left(m^{2}\right) ; l_{f}$ is the friction loss $\left(M P_{a} / m\right)$.

\subsection{Model solution}

The iterative method was adopted to solve the model, considering the variations of the density, viscosity, and thermal conductivity of supercritical steam with temperatures and pressures [14]. Solving formula (9), we have:

$$
\begin{aligned}
& T_{s}(y)=c \cdot \exp \left(-\frac{2 \pi r_{2} U \lambda_{e}}{W C_{p}\left[\lambda_{e}+r_{2} U f(t)\right]} y\right)+T_{e} \\
& -\frac{G}{\frac{2 \pi r_{2} U \lambda_{e}}{W C_{p}\left[\lambda_{e}+r_{2} U f(t)\right]}}
\end{aligned}
$$

The wellbore was divided into several microsecond sections, and solved by nodal analysis. The initial conditions were set as: $y=y_{\text {in }}, T_{s}=T_{\text {in }}$ and $T_{e}=T_{\text {ein }}$ [15]. Substituting these conditions into formula (11), we have:

$$
c=\frac{T_{\text {in }}-T_{\text {ein }}+\frac{G}{\frac{2 \pi r_{2} U \lambda_{e}}{W C_{p}\left[\lambda_{e}+r_{2} U f(t)\right]}}}{\exp \left(-\frac{2 \pi r_{2} U \lambda_{e}}{W C_{p}\left[\lambda_{e}+r_{2} U f(t)\right]}\right) y_{i n}}
$$

Then, the temperature of each small outlet node can be expressed as:

$$
\begin{aligned}
& T_{\text {out }}=T_{e}+\left(T_{\text {in }}-T_{\text {ein }}+\frac{G}{\left.\frac{2 \pi r_{2} U \lambda_{e}}{W C_{p}\left[\lambda_{e}+r_{2} U f(t)\right]}\right)}\right. \\
& \exp \left[-\frac{2 \pi r_{2} U \lambda_{e}}{W C_{p}\left[\lambda_{e}+r_{2} U f(t)\right]}\left(y_{\text {out }}-y_{\text {in }}\right)\right] \\
& -\frac{G}{\frac{2 \pi r_{2} U \lambda_{e}}{W C_{p}\left[\lambda_{e}+r_{2} U f(t)\right]}}
\end{aligned}
$$

\section{CASE STUDY}

To verify the proposed model, a case study was performed on the supercritical steam injection well L31513 in Lukeqin Oilfield.

\subsection{Initial parameters}

(1) Formation parameters

The reservoir temperature is $25^{\circ} \mathrm{C}$, the reservoir depth is $220.5 \mathrm{~m}$, the surface temperature is $19.5^{\circ} \mathrm{C}$, the formation thermal conductivity is $2.28 \mathrm{~W} / W / m^{2}{ }^{0} \mathrm{C}$, and the surface temperature gradient is $0.025^{\circ} \mathrm{C} / \mathrm{m}$;

(2) Gas injection parameters

Under the pressure of $33 \mathrm{MPa}$ and the temperature of $390^{\circ} \mathrm{C}$, the gas was injected at the rate of $5.5 \mathrm{t} / \mathrm{h}$ for $7.6 \mathrm{~d}$. The steam was $100 \%$ dry.

(3) Parameters of tube casing and cement annulus

The same tube was used for steam injection and oil recovery. For the tube, the inner diameter is $0.062 \mathrm{~m}$, the outer diameter is $0.073 \mathrm{~m}$, and the thermal conductivity is $37 \mathrm{~W} / \mathrm{m}^{2}{ }^{0} \mathrm{C}$. For the casing, the inner diameter is $0.1598 \mathrm{~m}$, the outer diameter is $0.1778 \mathrm{~m}$, and the thermal conductivity is $40 \mathrm{~W} / \mathrm{m}^{2}{ }^{0} \mathrm{C}$. For the cement annulus, the inner diameter is $0.18 \mathrm{~m}$, the outer diameter is $0.24 \mathrm{~m}$, and the thermal conductivity is $0.3 \mathrm{kcal} /\left(\mathrm{m}^{2} \cdot h \cdot{ }^{\circ} \mathrm{C}\right)$. The annular medium is air with a thermal conductivity of $0.06 \mathrm{~W} / \mathrm{m}^{2} \cdot{ }^{\circ} \mathrm{C}$.

\subsection{Software interface}

Based on the previous discussions, the author compiled a software for the calculation of temperature and pressure during the supercritical CSS.

(1) Steam dryness and heat loss

The calculation interface of the dryness and heat loss of the supercritical steam is presented in Figure 17.

(2) Temperature distribution of casing and cement annulus

The calculation interface of the temperature distribution in the casing and cement annulus is illustrated in Figure 13.

(3) Temperature and pressure of supercritical steam

The calculation interface of the temperature and pressure of the supercritical steam injected into the wellbore is given in Figure 19. 


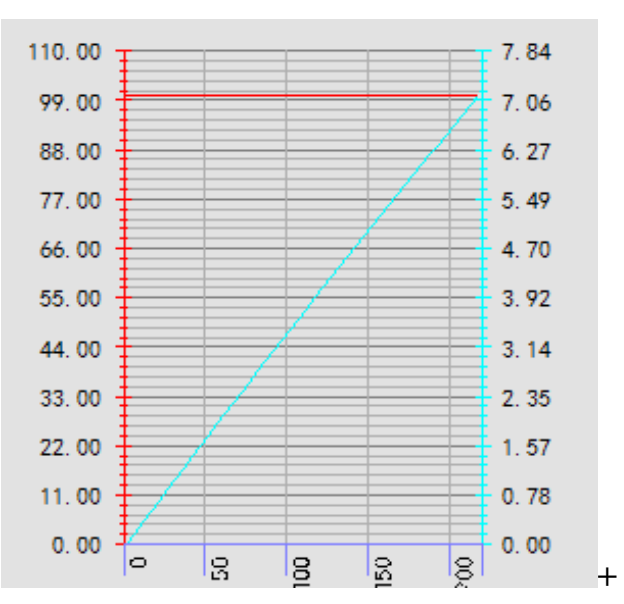

Figure 17. The calculation interface of the dryness and heat loss of the supercritical steam

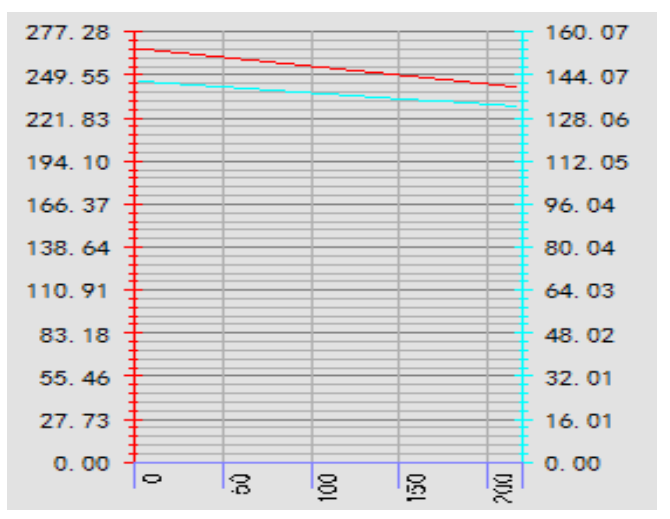

Figure 18. The calculation interface of the temperature distribution in the casing and cement annulus

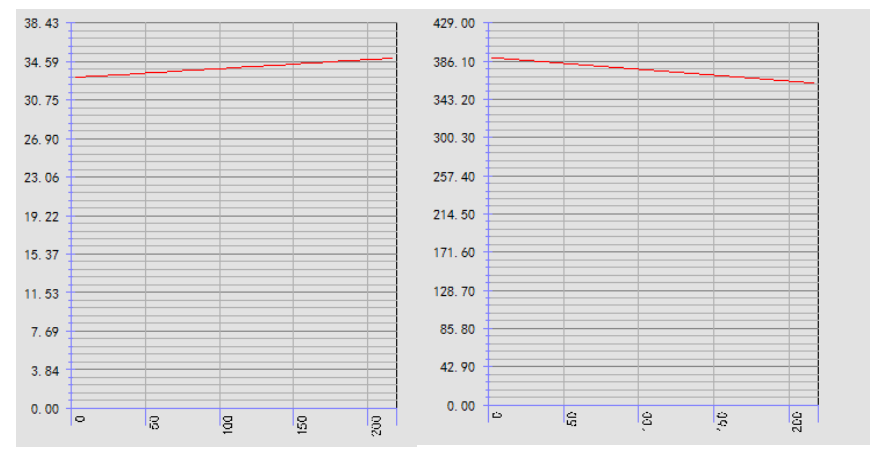

Figure 19. The calculation interface of the temperature and pressure of the supercritical steam

\subsection{Results analysis}

The temperature and pressure distributions of L13315 well, Lukeqin Oilfield were calculated with our model, and compared with the measured data. As shown in Figures 20 and 21 , the calculated temperature of wellbore steam decreased linearly, while the calculated pressure of the steam increased linearly, with the increase of well depth. The calculation results are consistent with the distribution curves of the test results. The error between the two sets of results is extremely small $(<1,500 \mathrm{~m})$, indicating that the proposed model can guide the design of the supercritical CSS parameters in the oilfield.

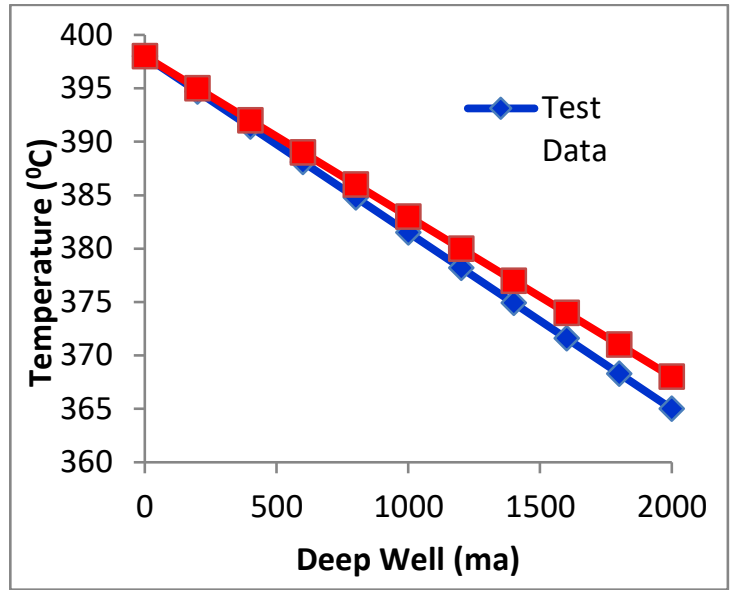

Figure 20. Comparison of calculated and measured temperatures

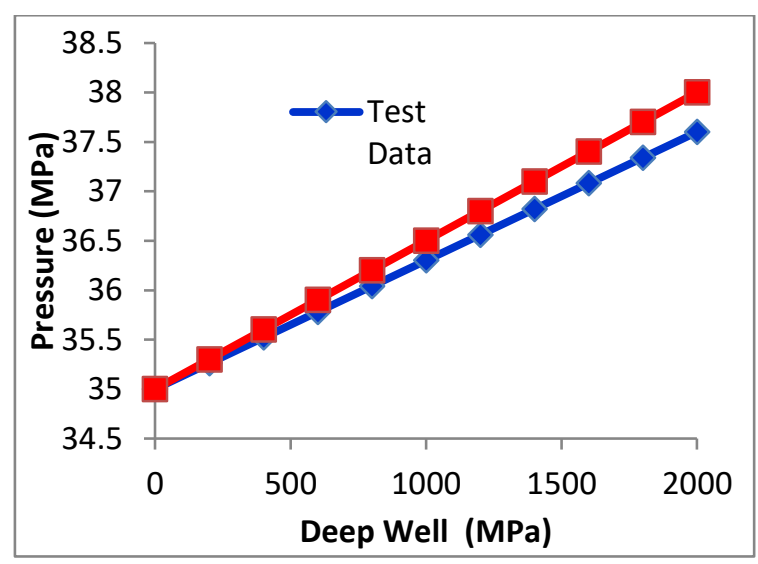

Figure 21. Comparison of calculated and measured pressures

\section{CONCLUSIONS}

This paper acquires the variations of the supercritical steam parameters (i.e. density, viscosity, thermal conductivity, enthalpy and specific heat) with temperatures and pressures, plots the 3D diagrams of the variation patterns, and performs surface fittings of the results. On this basis, the calculation formulas were put forward for the physical parameters of steam under changing temperature and pressure.

According to the theories of heat transfer, thermodynamics and fluid mechanics, the author created the mathematical model of wellbore temperature and pressure in supercritical CSS, and discretized the calculation formulas by node analysis.

Based on the model, a computation software was compiled for supercritical CSS, and applied to calculate the variation in wellbore temperature and pressure with well depths. The results show that the calculated temperature of wellbore steam decreased linearly, while the calculated pressure of the steam increased linearly, with the increase of well depth.

Through comparison, the calculated results were found to be consistent with the distribution curves of the test results. The error between the two sets of results is extremely small $(<1,500 \mathrm{~m})$, indicating that the proposed model can guide the design of the supercritical CSS parameters in the oilfield. 


\section{ACKNOWLEDGEMENTS}

Part of this work is supported by the Natural Science Foundation of College of Technology \& Engineering, Yangtze University (2017KY02).

\section{REFERENCES}

[1] Hui H, Li D. (2013). Evaluation of supercritical steam soaking of viscous crude oil in eastern luke district. Liaoning Chemical Industry 12(9): 1112-1114.

[2] Yang YZ. (2012). Test and application of Lukeqin oilfield $35 \mathrm{MPa}$ supercritical steam injection. China Petroleum and Chemical Standard and Quality 32(1): 148-149.

[3] Zhang R. (1999). China Reservoir Management Technology Handbook for Thermal Recovery Of Heavy Oil. Petroleum Industry Press, Beijing, 125-138.

[4] Ambethkar V, Kumar M. (2017). Numerical solutions of 2-D unsteady incompressible flow with heat transfer in a driven square cavity using streamfunction-vorticity formulation. International Journal of Heat and Technology 35(1): 459-473. https://doi.org/ 10.18280/ijht.350303.

[5] Kalinichev AG. (1999). Molecular dynamics of supercritical water: A computer simulation of vibrational spectra with the flexible BJH potential. Geochimica Et Cosmochimica Acta 59(4): 641-650.

[6] Yutaka I, Hatakeda K, Satio N. (1998). An in situ Raman spectroscopy study of subcritical and supercritical water: The peculiarity of hydrogen bonding near the critical point. Journal of Chemical Physics 108(14): 5855-5860.

[7] Sarma PK, Konijeti R, Subramanyam T, Prasad LSV, Korada VS, Srinivas V, Vedula DR, Prasad VSRK.
(2017). Fouling and its effect on the thermal performance of heat exchanger tubes. International Journal of Heat and Technology 35(1): 509-519. https://doi.org/ 10.18280/ijht.350307

[8] Gorbaty YE, Kalinichev AG. (2005). Hydrogen bonding in supercritical water.1.experimental result. Journal of Physical Chemistry 15(10): 101-122.

[9] Ramey H. (1962). Wellbore heat transmission. Journal of Petroleum Technology 14(4): 427-435.

[10] Willhite T. (1967). Over-all heat transfer coefficients in steam and hot water injection wells. Journal of Petroleum Technology 19(5): 607-615.

[11] Srinivasacharya D, Shafeeurrahman M. (2017). Joule heating effect on entropy generation in MHD mixed convection flow of chemically reacting nanofluid between two concentric cylinders. International Journal of Heat and Technology 35(1): 487-497. https://doi.org/ 10.18280/ijht.350305

[12] Mao W, Liang Z. (1999). A new method for calculating the temperature distribution in a well bore of a gas well. Journal of Southwest Petroleum Institute 21(1): pp. 5658 .

[13] Banica M, Medan N. (2015). Statistical analysis of the experimentaldata obtained in studying of water jet cleaning. Academic Journal of Manufacturing Engineering 13(1): 6-11.

[14] Liu HB, Cheng LS, Song LX. (2014). Method of calculation of temperature and pressure in supercritical gas injection well field. Journal of Petroleum University, Natural Science Edition 28(1): 52-54.

[15] Ghernaout B, Ghernaout D, Bouabdallah S, Atia A. (2016). Two transitions of thermosolutal natural convection in the presence of an external magnetic field. Mathematical Modelling of Engineering Problems 4(3): 120-125. 